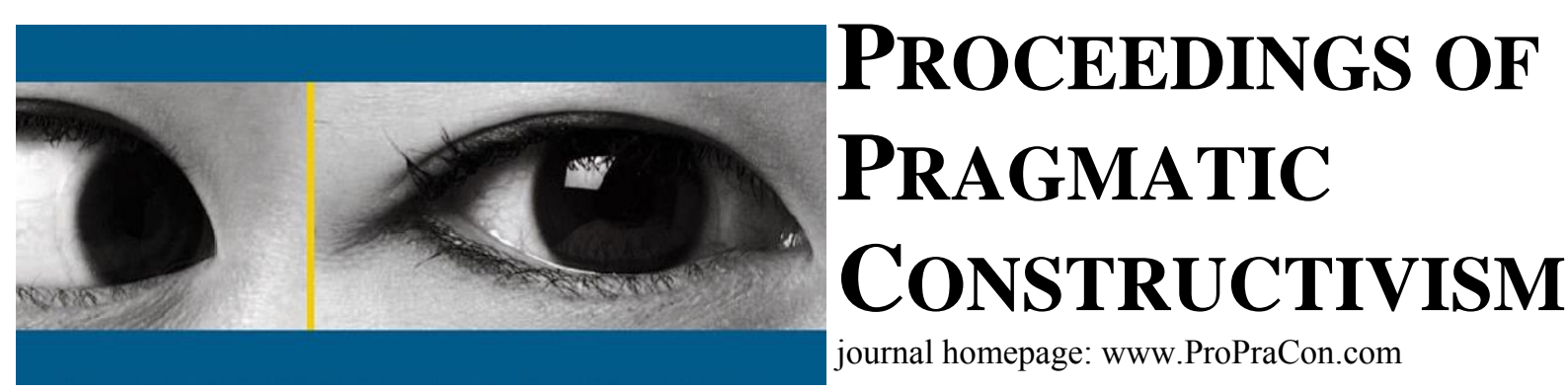

\title{
The process of producing annual reports - Models derived from consultants' narratives
}

\author{
Gunnar Rimmel \\ Associate Professor of Accounting \\ University of Gothenburg; School of Business, Economics and Law \\ Vasagatan, 40530 Göteborg, Sweden; gunnar@rimmel.se \\ Kristina Jonäll \\ Assistant Professor of Accounting \\ University of Gothenburg; School of Business, Economics and Law \\ Vasagatan, 40530 Göteborg, Sweden; kristina.jonall@handels.gu.se \\ Inga-Lill Johansson \\ Associate Professor of Accounting \\ University of Gothenburg; School of Business, Economics and Law \\ Vasagatan, 40530 Göteborg, Sweden; inga-lill.johansson@handels.gu.se
}

\begin{abstract}
Annual reports are an important means of communication for companies. Readers use the information in the annual report to form a general picture of a company. In general, not many readers of annual reports reflect that this document is, apart from the numbers in the accounts, in large parts outsourced to public relations companies.

Although information content of corporate annual reports have been studied in many way the production process has been absent in accounting research so far. The purpose of this article is to describe and examine the process of producing annual reports as a means of communication for listed Swedish corporations. This study focuses on the interplay between the corporation's personnel and the public relations agency. An examination of the annual report production process shows elements that are most useful in describing the communication process. A systematic review of the annual report production process necessitates the development of a model which will organize the complex elements of communication that derives from the interaction of the multinational with its public relations agency.

The analysis shows that there is interplay between a listed company and public relations agency that makes aims to produce a certain picture among the readers of annual reports. However, it is not possible to draw a strict line that public relations work is solely limited to layout and pictures. In some cases of annual report production, a listed company is heavily influenced and open to suggestions by the specific knowledge of a public relations company, when it comes to content and structure of texts numbers. Therefore, it is important to understand the process of annual report production as an interplay between the company and public relations professionals, as the annual report is contributing to maintain legitimacy, creating trust and confidence in the company and the activities it engages in.
\end{abstract}

Keywords: Annual reports; disclosure theory; stakeholder theory; legitimacy theory; public relations; production process; Sweden.

Acknowledgement: The authors are grateful to the Handelsbanken Research Foundation for funding this project. 


\title{
The Process of Producing Annual Reports
}

\section{-Models derived from consultants' narratives}

\author{
Gunnar Rimmel \& Kristina Jonäll \\ \& Inga-Lill Johansson
}

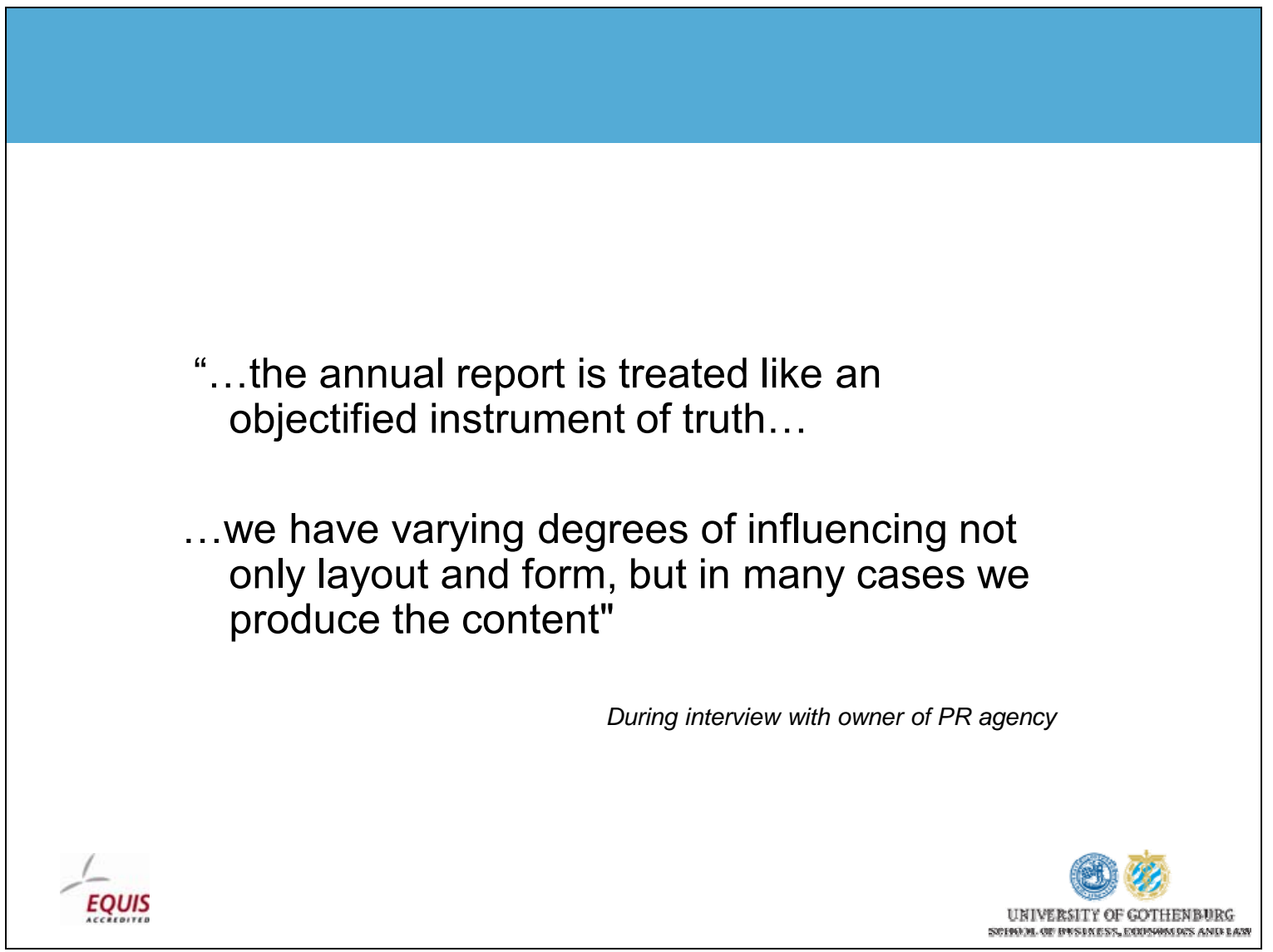




\section{Background}

The corporate annual report is the only source of information available to each stakeholder group

Not many readers of corporate annual reports reflect that the production of the important corporate document is, apart from the numbers in the accounts, in large parts outsourced to public relations agencies that have specialist knowledge and professional production know-how.

Over $95 \%$ of all Swedish listed companies involve PR agencies for the annual report production process

\section{Purpose}

It is important to understand the role of communication consultants on designing corporate information content and their role on disclosure and accountability in corporate annual reports

The general aim of this study is to widen the scope of accounting research in two key directions.

1. Illustrate an annual report production process model between listed companies with public relation agencies

2. Investigate how this model might challenge different strands of accounting research like disclosure theory, stakeholder theory and legitimacy theory 


\section{Objective of reporting \& theories}

The objective of any corporate report is to communicate timely, reliable and relevant information about an organization to a wide range of user groups of corporate reporting

\section{Disclosure theory}

theoretically rooted in economic justifications that disclosure of information underlies agency and information problems, which impeded capital markets optimal allocation of resources .

Disclosure scoreboards common method.

\section{Stakeholder theory}

The nature of the relationship that each group has with the company varies, as do the decisions that each group takes concerning the company.

The relationship between stakeholder trust and company information is of particular importance.

\section{Legitimacy theory}

closely linked to stakeholder theory. Most widely used to explain the presence of supplementary information in the financial statements (Gray et al., 1995). The perception of the social contract is used to reflect society's expectations of how organizations should conduct its operations or supply information.

\section{Method}

Although Swedish companies normally are very open minded to research, granting access to most secretive corporate areas, it was an impossible mission to convince listed companies to participate observing their annual report production.

Here this research would have ended; if not public relation agencies would have found interest on the subject of this research.

A number of senior consultants specialised in the production of corporate annual reports participated in interviews, where they spoke uninterrupted about their experience from the interplay between the public relations agency and the listed corporations during the annual report production process.

The generic model of corporate annual report production was developed after these interviews and modified towards different sizes of listed companies.

In follow-up meetings to refine model. 


\section{Involvement of PR agencies in Small listed companies}

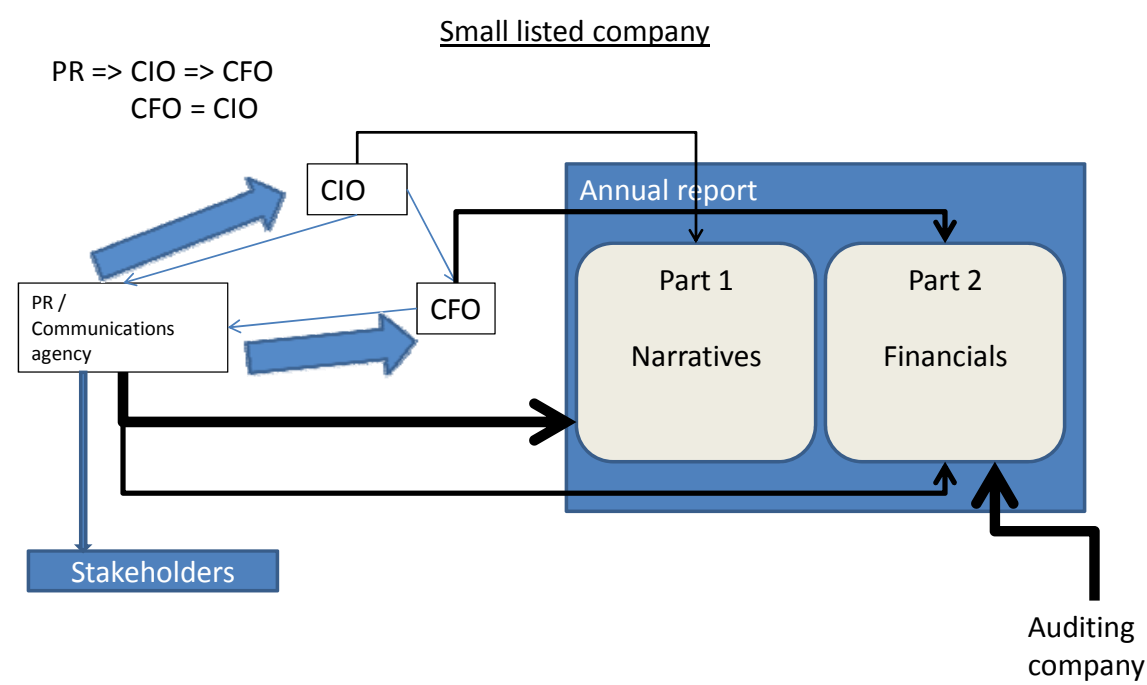

$\frac{1}{E Q U I S}$

\section{Involvement of PR agencies in Medium sized listed companies}

$$
\mathrm{PR}=>\mathrm{CIO}=>\mathrm{CFO} \quad \underline{\text { Medium listed company }}
$$

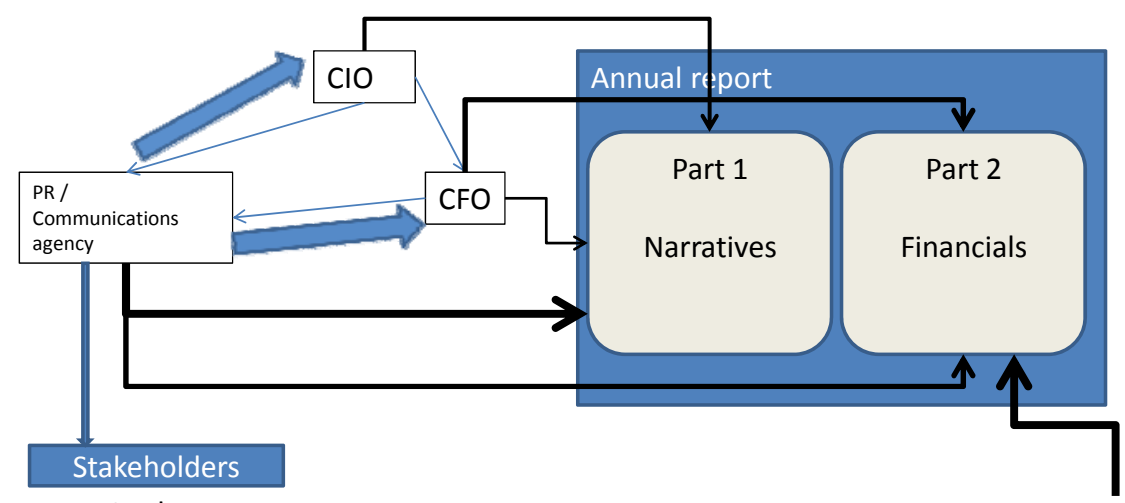

$=$ Analysts 


\section{Involvement of PR agencies in Large sized listed companies}

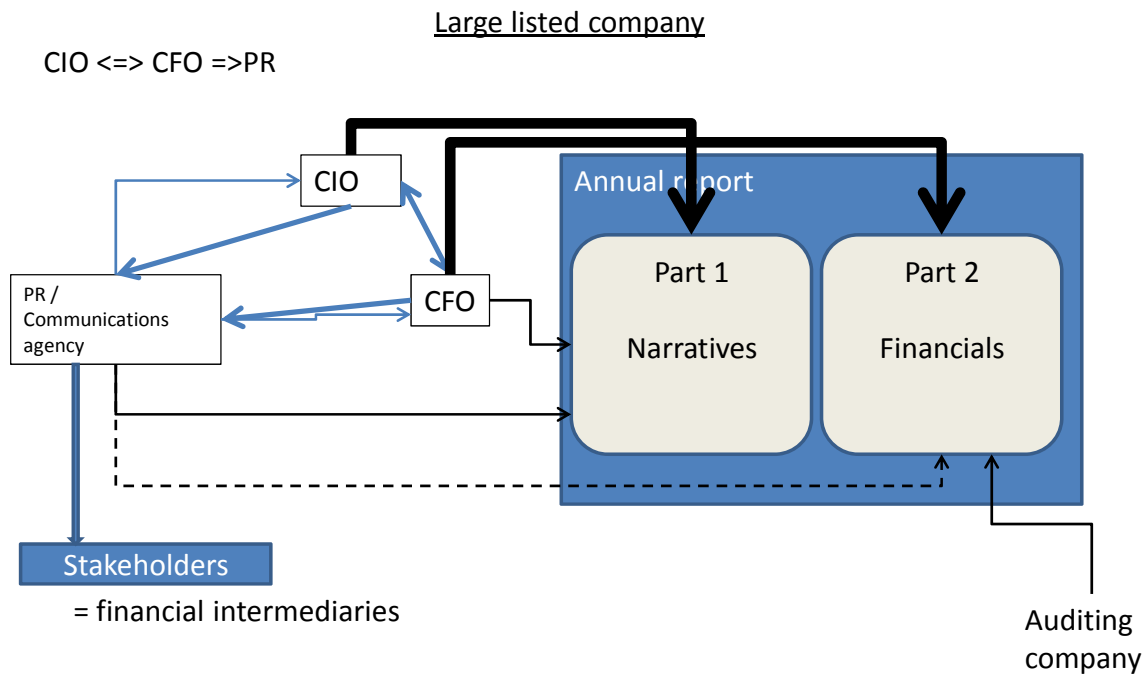

\section{Summary of results}

It is unlikely that the interplay between listed corporations and public relations agencies have no implications on the information disclosed in corporate annual reports or how information preferences of different stakeholder groups have been served.

Disclosure research has missed the fact that the involvement and the large influence of public relation agencies on small and medium size listed companies might lead to fact that specific types of information might be disclosed more frequently.

Listed companies are not considering a multitude of different stakeholder groups but merely analysts or financial intermediaries.

For small and medium sized listed corporations the disclosed information not necessarily originates from management but a well versed copy writer. Therefore, it could be questioned how systematically corporations work on legitimising their actions towards different groups in society when it comes to the disclosed information in annual reports. 